\title{
ANÁLISE AMBIENTAL E PROCESSO DE DESERTIFICAÇÃO NO SERTÃo SEMIÁRIDO: EXPLICAÇÃO A PARTIR DOS DADOS SOCIOECONÔMICOS
}

\author{
Carine Fonseca Menezes Silva ${ }^{1}$; Nacelice Barbosa Freitas ${ }^{2}$; \\ 1. Bolsista PIBIC/FAPESB, Graduanda em bacharelado do curso de Geografia, Universidade Estadual de Feira de Santana, \\ e-mail: carinemeneze@gmail.com \\ 2. Orientador, Departamento de Ciências Humanas e Filosofia, Universidade Estadual de Feira de Santana, e-mail: \\ nacegeografic@hotmail.com
}

PALAVRAS-CHAVE: Sertão; Semiárido; Pólo de Jeremoabo.

\section{INTRODUÇÃO}

O texto tem por objetivo analisar o processo de desertificação no sertão semiárido, especificamente Pólo de Jeremoabo, tendo como referência os dados socioeconômicos, especialmente o Produto Interno Bruto (PIB) e o Rendimento Médio Mensal.

A Região Nordeste ocupa aproximadamente uma área de $1.556 .000 \mathrm{~km}^{2}$ do território nacional, e caracteriza-se pela diversidade socioambiental decorrentes das condições naturais, apresentando clima tropical úmido, tropical subúmido, e semiárido. O sertão é uma sub-região do Nordeste, ocupando aproximadamente $11,5 \%$ da extensão territorial do país, e devido à relação sociedade-natureza, associado ao baixo nível técnico aplicado as práticas agrícolas, diversas áreas encontram-se suscetíveis ao processo de desertificação. Sendo assim, torna-se necessário o desenvolvimento de pesquisas relacionadas a problemática regional, pois o Nordeste abriga aproximadamente $30 \%$ da população do país, levando a Ab'Saber (2003) afirmar que o Brasil detém o semiárido mais povoado do mundo.

A finalidade do resumo é oferecer informações acerca da problemática da desertificação do sertão e semiárido baiano, a partir dos dados obtidos durante a pesquisa de iniciação científica, tendo em vista a explicação acerca dos discursos socialmente construídos que criam um imaginário social sobre essa sub-região, onde esse espaço é caracterizado como o território da seca, da pobreza, e da exclusão social.

\section{MATERIAL E MÉTODOS}

O Pólo de Jeremoabo localiza-se no semiárido baiano e conta com treze municípios: Antas, Canudos, Chorrochó, Coronel João Sá, Glória, Jeremoabo, Macururé, Novo Triunfo, Paulo Afonso, Pedro Alexandre, Rodelas, Santa Brígida, e Uauá estes apresentam vulnerabilidade socioambiental, estando localizados em área propensa à desertificação. (FIGURA 1). De acordo com Sá (2010), o semiárido baiano caracteriza-se pela forte insolação, temperaturas relativamente altas $24^{\circ} \mathrm{C}$ em média, e regime de chuvas marcado pela escassez, irregularidade, e concentração das precipitações em um curto período, em média de três a quatros meses.

Para a realização da pesquisa foi elaborado um levantamento bibliográfico, em decorrência da necessidade de aprofundamento teórico-conceitual para as discussões, e construções das análises a partir dos dados obtidos. Em seguida coletou-se os dados do Produto Interno Bruto (PIB) de 2010 e Rendimento Médio Mensal dos municípios que integram o Pólo de Jeremoabo, no Instituto Brasileiro de Geografia e Estatística (IBGE), para em seguida mapear por meio dos softwares de geoprocessamento Arc View e Arc Map 10. As diferentes etapas da pesquisa visam estabelecer comparação entre as informações colocadas nos mapas, e a organização de um banco de dados com os resultados obtidos, possibilitando uma reflexão sobre o processo de desertificação no sertão e semiárido. 


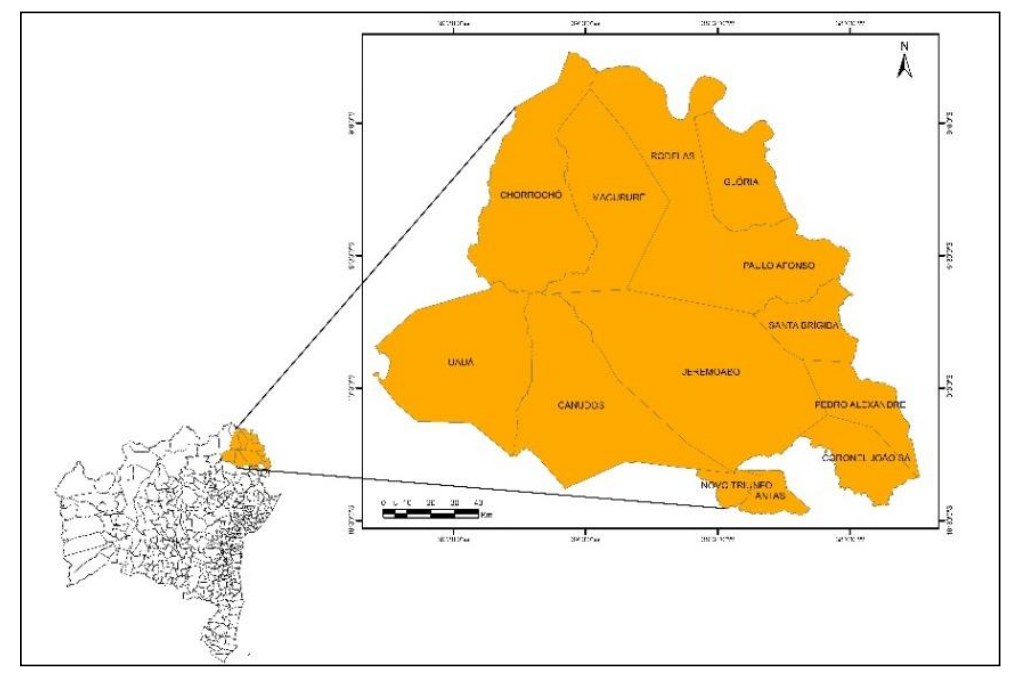

Fonte: Censo Demográfico do Instituto Brasileiro de Geografia e Estatística (IBGE-2010) Figura 1: Pólo de Jeremoabo: Localização no Estado da Bahia

\section{RESULTADOS E DISCUSSÃO}

Os municípios do Pólo de Jeremoabo localizam-se na região semiárida da Bahia, em meio as relações conflituosas e de poder, onde prevalecem os interesses das elites A população total do Pólo, segundo os dados do censo demográfico do Instituto Brasileiro de Geografia e Estatísticas (IBGE-2010), corresponde a aproximadamente 309 mil habitantes, com população rural de cerca de 130 mil habitantes, representando $43 \%$ da população total, enquanto a população urbana representa 57\%, somando mais de 174 mil habitantes.

Segundo Conti $(1992$, p.33) a "desertificação é um conjunto de fenômenos que conduz determinadas áreas a transformar-se em desertos ou a eles se assemelharem. Origina-se da pressão intensa de atividades humanas sobre ecossistemas frágeis ou de mudanças climáticas determinadas por causas naturais".

Segundo Coimbra (2013) o PIB representa o resultado final da atividade econômica dos residentes num determinado território, num dado período de tempo. Ao analisar os dados do Produto Interno Bruto do Pólo de Jeremoabo percebe-se que a degradação do solo pelo uso intensivo, o desmatamento, as queimadas e as práticas inadequadas na agricultura nos municípios, contribuíram para estabelecer a vulnerabilidade ambiental, tornando-os susceptíveis ao processo de desertificação, consequentemente há perda da potencialidade agrícola do solo, resultando no declínio da produtividade, isso é perceptível nos dados relacionados ao PIB municipal. (FIGURA 2).

Macururé e Rodelas apresentaram em 2010, PIB inferior a R \$ 50.000,00 (cinquenta mil reais). Vale salientar que estes municípios são os dois menos populosos do Pólo, com menos de 10.000 (dez mil habitantes). Chorrochó, Glória, Santa Brígida, Pedro Alexandre, Canudos, Novo Triunfo, Antas, e Canudos registram PIB entre R \$ 50.000,00 (cinquenta mil reais) e R\$ 100.000,00 (cem mil reais), e Paulo Afonso, Jeremoabo, Coronel João Sá e Uauá estão na classe que indica o PIB superior a 100.000,00 (cem mil reais), identificando-se que Paulo Afonso é o município do Pólo de Jeremoabo de maior participação no PIB. (FIGURA 2).

Ao analisar os indicadores socioeconômicos dos municípios do Pólo de Jeremoabo, percebe-se a diversidade nos valores registrados quanto ao PIB. Isso decorre de diversos fatores dentre eles, a vulnerabilidade ambiental, em consequência da fragilidade das políticas públicas para as populações que vivem no sertão semiárido. Lourenço \& Romero (2011) afirmam que os indicadores econômicos (IEs) representam dados que indicam o comportamento (individual ou integrado) das diferentes variáveis e fenômenos componentes de um sistema econômico. Os 
IEs são fundamentais para analisar as características econômicas, subsidiando o processo de tomada de decisões dos agentes públicos e privados.

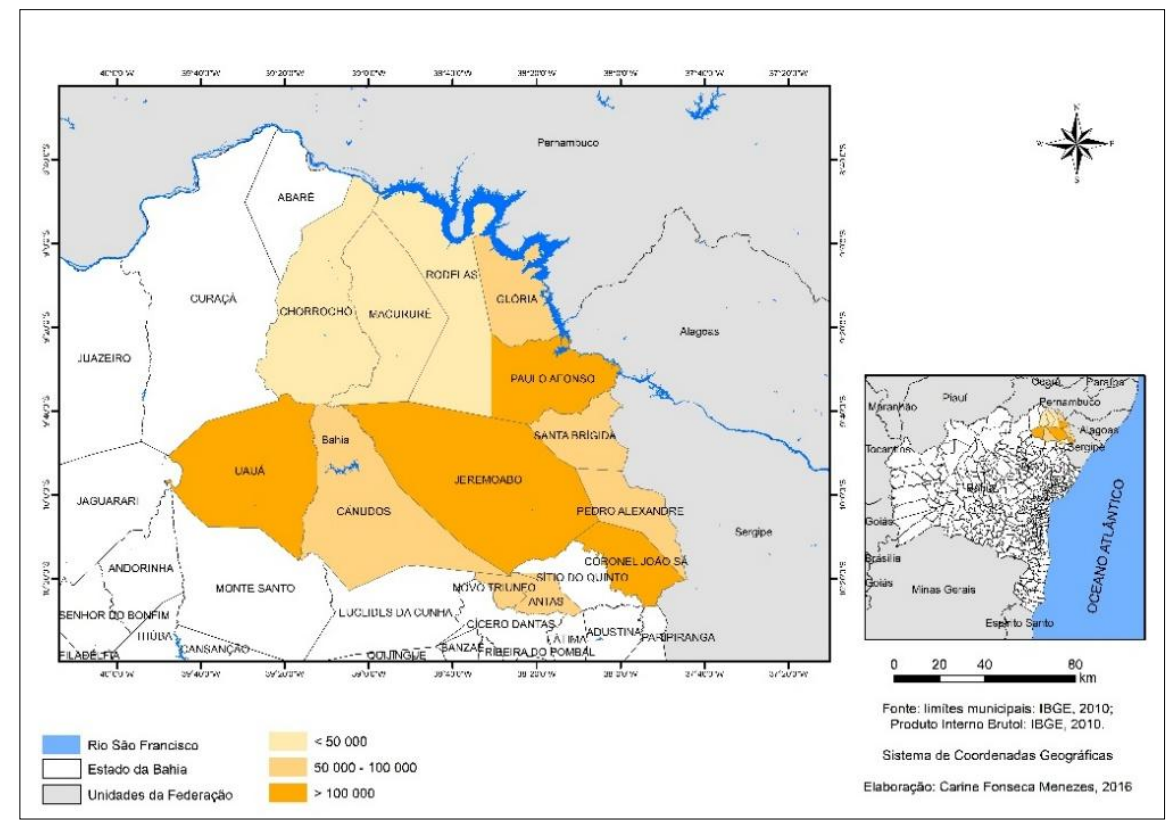

Figura 2: Produto Interno Bruto do Pólo de Jeremoabo, 2010.

As análises dos números referentes ao Rendimento Médio Mensal urbano e rural de 2010, dos municípios que integram o Pólo de Jeremoabo encontram-se sistematizados na tabela 1. Pedro Alexandre apresenta o menor rendimento médio mensal rural e urbano, ou seja, $\mathrm{R} \$$ 621,00 (seiscentos e vinte e um) reais no espaço rural, e no espaço urbano o valor de $\mathrm{R} \$ 952,00$ (novecentos e cinquenta e dois) reais. Paulo Afonso caracteriza-se como o município de maior rendimento médio mensal rural e urbano registrando o valor de $\mathrm{R} \$ 864,39$ (oitocentos e sessenta e quatro) reais no espaço rural, e urbano igual a $\mathrm{R} \$ 2.095,00$ (dois mil, e noventa e cinco) reais. Esses dados refletem as desigualdades entre os rendimentos médios mensais no Pólo de Jeremoabo, justificando a necessidade de planejamento e ordenamento territorial, tendo em vista a vulnerabilidade ambiental.

\begin{tabular}{l|c|c}
\hline \multicolumn{1}{c|}{ Município } & $\begin{array}{c}\text { Domicílio } \\
\text { Rural }\end{array}$ & $\begin{array}{c}\text { Domicílio } \\
\text { Urbano }\end{array}$ \\
\hline Antas & 843,84 & $1.497,86$ \\
Canudos & 658,96 & $1.153,82$ \\
Chorrochó & 854,37 & $1.448,34$ \\
Coronel João Sá & 695,60 & $1.072,99$ \\
Glória & 864,39 & $2.065,52$ \\
Jeremoabo & 660,29 & $1.242,07$ \\
Macururé & 780,50 & $1.252,19$ \\
Novo Triunfo & 684,13 & $1.088,92$ \\
Paulo Afonso & 864,39 & $2.095,52$ \\
Pedro Alexandre & 621,88 & 952,02 \\
Rodelas & 810,83 & $1.066,70$ \\
Santa Brígida & 680,78 & $1.030,26$ \\
Uauá & 643,12 & $1.238,12$ \\
\hline
\end{tabular}

Fonte: Censo Demográfico do Instituto Brasileiro de Geografia e Estatística (IBGE-2010)

Tabela 1. Rendimento médio mensal urbano e rural dos municípios do Pólo de Jeremoabo - 2010 
A desertificação é uma problemática que atinge os municípios do Pólo, assim o setor da agropecuária é o mais atingido, podendo-se observar que apresenta a menor contribuição para o PIB. O setores de serviço confere a maior contribuição do PIB regional, e a indústria aparece em segundo lugar - Cabe ressaltar que a atividade industrial é mais significativa em Paulo Afonso devido a presença da Companhia Hidroelétrica de São Francisco (CHESF).

\section{CONSIDERAÇÕES FINAIS}

A distribuição espacial da população do Pólo de Jeremoabo explica a relevância da agropecuária para o sustento das famílias; dos treze municípios que compõem o Pólo, onze apresentam uma população residente no espaço rural superior aos residentes no urbano. A agropecuária é o setor de menor contribuição para o PIB em valores absolutos, aspecto considerado significativo, visto que as atividades agropastoris caracterizam-se como a mais importante para o sustento das famílias. Esses dados reforçam a necessidade de implementação políticas públicas para a melhoria da qualidade de vida dos habitantes. O ordenamento territorial pode ser considerado uma alternativa, a ser executada visando a inserção de infraestrutura, programas projetos específicos para o sertão semiárido.

O texto da Carta Européia do Ordenamento do Território (1984), expõe que ordenar o território é compatibilizar o desenvolvimento socioeconômico equilibrado das regiões com a melhoria da qualidade de vida, com a gestão responsável dos recursos naturais, e a utilização racional dos solos. Nessa perspectiva, o Pólo carece de projetos que viabilizem o planejamento voltado para a população, pois os municípios estão em situação de vulnerabilidade, ou seja, são propensos ao processo de desertificação.

Segundo Castro (1992), a perspectiva de que residem nas dificuldades impostas pela sua natureza a principal causa dos problemas do semiárido nordestino, tem sido um recurso discursivo que, partindo da elite intelectual e política, compromete toda a sociedade. A autora afirma que a natureza semiárida, é exemplarmente apropriada pelo imaginário coletivo através de imagens que são retrabalhadas na produção intelectual na e sobre a Região, dando suporte ao discurso e aos atos políticos.

Dessa forma, as elites historicamente beneficiadas pelas condições estruturais da região nordeste, utilizam-se do discurso da "necessidade" para obtenção de verbas do governo federal, perpetuando-se como as elites do/no poder. Nesse sentido, é de fundamental importância a implementação de políticas públicas específicas do sertão semiárido, especialmente para o Pólo de Jeremoabo, que visem o ordenamento territorial, que tenham por meta a desconstrução desses discursos no sentido de possibilitar uma nova definição do sertão nordestino, sobretudo no semiárido baiano.

\section{REFERÊNCIAS}

AB'SÁBER, A. Os domínios de natureza no Brasil: potencialidades paisagísticas. São Paulo: Ateliê Editorial, 2003.

CASTRO, Iná Elias de. O mito da necessidade. Discurso e prática do regionalismo nordestino. Bertrand, Rio de Janeiro, 1992.

CEOT/CEMAT. “A Regional/Spatial Charter for Europe”. Estrasburgo: Conselho de França. 1984.

CONTI, J.B. Desertificação nos Trópicos: proposta de metodologia aplicada ao Nordeste Brasileiro, Tese de Livre Docência - USP, São Paulo,1992.

IBGE, Instituto Brasileiro de Geografia e Estatística. Censo Demográfico. 2010.

SÁ, Iêdo Bezerra; SILVA, Pedro Carlos Gama. Semiárido Brasileiro: pesquisa, desenvolvimento e inovação. Pernambuco: Embrapa Semi-Árido, 2010, 402 p. 